\title{
MATERIALISMO E PRIMADO DO OBJETO EM ADORNO
}

Wolfgang Leo MAAR ${ }^{2}$

- RESUMO: Este artigo investiga a "Tese" do primado do objeto na obra de Theodor W. Adorno, central ao seu materialismo não dogmático e relativamente pouco estudada. O primado do objeto será apresentado em seus elementos constitutivos, como crítica ao modo essencialmente idealista da dialética que perpassa o conjunto da obra de Adorno, em especial nos textos e discussões que precederam a publicação da Dialektik der Aufklãrung, para se explicitar no período de elaboração da Negative Dialektik. A "Tese" desenvolve momentos apresentados por Lukács, Benjamin e Horkheimer, particularmente quanto ao nexo entre razão e experiência e se fundamenta especialmente no trajeto Kant - Hegel, como crítica ao idealismo, incorporando de modo estruturante as perspectivas de Marx e de Nietzsche. Ao romper a pretensa "simetria" entre sujeito e objeto, a "Tese" do primado do objeto revela como é insustentável a alegação habermasiana do Discurso filosófico da modernidade segundo a qual Adorno e Horkheimer incidiriam num ceticismo total frente à razão e à sua totalização ideológica. Ao contrário: estes autores, ao articularem de um modo original substância material histórica e argumentação teórica, contribuíram de modo fundamental para examinar o problema da reificação mediante sua relação à objetividade - como o não-idêntico - no âmbito da razão.

- PALAVRAS-CHAVE: Adorno; Materialismo; Dialética negativa; Primado do objeto; Teoria Crítica.

1 Uma versão deste texto foi parte de um projeto de pesquisa apresentado ao CNPq.

2 Professor Titular do Departamento de Filosofia e Metodologia das Ciências e do Programa de PósGraduação em Filosofia da Universidade Federal de São Carlos-UFSCar. Artigo recebido em set/ 06 e aprovado para publicação em out/06. 


\section{Apresentação}

O primado do objeto constitui a "tese" central que orienta a filosofia de Theodor Adorno em sua retomada do trajeto Kant-Hegel. Esse trajeto se impõe porque nele adquiriu sua expressão acabada o idealismo e sua focalização dos nexos entre sujeito e objeto na relação entre pensamento e realidade efetiva.

O primado ou a prioridade do objeto é a "tese" que, conforme Adorno, deve se dispor no lugar da "tese" da Revolução Copernicana (Kopernikanische Wende), criticada no que esta representa de supremacia do sujeito na constituição do objeto, em especial a partir de Kant. Na obra de Adorno, o primado do objeto resulta da crítica aos pressupostos idealistas que, ao se manterem presentes na dialética, anulam o materialismo.

O intento de Adorno consistia em criticar a dialética idealista "por dentro"; isto é, acompanhar o que seria uma "crítica à razão instrumental" no âmbito "interno" à racionalidade, nas relações entre conceito e coisa. Pensar para Adorno é sempre pensar algo:

O que caracteriza propriamente a consciência é o pensar em relação à realidade, ao conteúdo: a relação entre as formas e estruturas do pensamento do sujeito e aquilo que este não é. Este sentido mais profundo de consciência ou faculdade de pensar não é apenas o desenvolvimento lógico formal, mas ele corresponde literalmente à capacidade de fazer experiências. (Adorno, 1995, p.151, grifo meu)

O objetivo fundamental do pensamento seria justamente apresentar o que é este algo, o objeto. Tendo em vista esta questão fundamental, Adorno percorre a tradição filosófica pautada na crítica ao idealismo.

Nesta iniciativa, Adorno se moveria entre dois parâmetros, que Horkheimer apresentaria como teoria tradicional e visão dogmática de mundo.

De um lado, Husserl, que, apesar de seu objetivo como orientação Zu den Sachen, fracassara segundo Adorno em seu programa de libertar-se dos pressupostos do idealismo, resultando numa apreensão abstrata da "coisa" pela via da intuição e da intencionalidade. O mesmo valeria para Heidegger, para quem o concreto acabaria apenas por legitimar a existência reificada. O positivismo, por sua vez, insistiria em uma descrição sustentada numa apreensão empírica fatual imediatista. Nessa medida, a filosofia contemporânea expressaria grandes dificuldades em sua relação com o mundo dos objetos empíricos, bem como com a própria apreensão adequada da experiência no âmbito da racionalidade.

Do outro lado, o materialismo dogmático e raso em sua ânsia de incidir na derivação material do pensamento. Em Crítica cultural e sociedade Adorno advertira que a determinação da consciência pelo ser fortalecera 
sobretudo o vigente, "escamoteando qualquer consciência discordante do existente" (Adorno, 1989, v.10-2, p.23).

Deste modo, por sua forma, seria impossível ao materialismo a apreensão adequada do sujeito, o que, aliás, Marx já constatara em sua $1^{2}$. Tese sobre Feuerbach:

A principal deficiência de todo materialismo até hoje (inclusive o de Feuerbach) é que objeto, a realidade efetiva só é apreendido sob a forma do objeto ou da intuição: e não como atividade humana no plano dos sentidos, práxis; não subjetivamente. Por isso o lado ativo seria desenvolvido pelo idealismo. (...) Feuerbach quer objetos no plano dos sentidos - distintos dos objetos "espirituais"; mas a atividade humana, ele não a apreende propriamente como atividade objetiva. (Marx \& Engels, 1966, v.1, p.139)

Neste texto a objetividade seria reduzida pelos termos das possibilidades já existentes e o que seria atividade, a subjetividade dialética, seria remetida ao utopismo. Nas discussões com integrantes do Instituto de Pesquisa Social que, a partir de 1939 constituirão a base do que posteriormente seria publicado como Dialektik der Aufklärung, Adorno assim se expressa acerca desta questão:

O conceito de dialética tem sido usado até hoje, inclusive na discussão marxista, de um modo essencialmente idealista, isto é, conclui-se a partir de um movimento conceitual e geral rumo ao movimento particular e específico na história. (...) Esta concepção é insuficiente, pois mesmo quando o conteúdo da doutrina afirma o contrário, por sua forma ela mantém a pretensão da subjetividade em dominar o mundo mediante seus conceitos. O problema da dialética, portanto, é determinado segundo dois aspectos: por um lado, a situação dada em que a reflexão deve se apoiar, também é constituída dialeticamente e não é um ponto de partida absoluto para a construção dialética. Por outro lado, esta construção dialética é inconseqüente, enquanto não estiver imediatamente presente a partir de uma análise da situação dada. (Horkheimer, 1985, v.12, pp.527-528)

Mais adiante Adorno explicaria que o conhecimento dialético deveria,

como co-portador de uma tensão, num certo sentido, ir além de si mesmo. Assim o conceito que é dado, já conteria em si o conceito do ir além de si. Nestes termos a tarefa de uma teoria da dialética seria situar o conceito do que é dado de tal modo que assim preencha esta função dialética. O meu conceito das "imagens dialéticas" (dialektische Bilder) corresponde a esta intenção. Refiro-me a "imagens" porque não se trata de um ser conceitual, mas de um ser imediatamente disponível, onde, entretanto, a disponibilidade imediata não seria definida exclusivamente mediante a percepção sensorial do sujeito, mas apreenderia em si determinadas condições sociais. Tais imagens são denominadas "dialéticas" porque, no sentido acima explicitado, sem que para sua construção houvesse necessidade de um ser conceitual geral, alcançam para além de si próprias, relacionando-se com outras situações históricas 
igualmente concretas sem abandonar seu âmbito concreto. Nesta medida há também outra forma de definir o problema das imagens dialéticas, aquela segundo a qual a tarefa da filosofia da história seria a de construir idéias que, sem ultrapassar o conjunto do material dado de modo confiável, detém mesmo assim poder revelador do ordenamento deste material na realidade efetiva. (Horkheimer, 1985, v.12, p.530)

Os pressupostos idealistas apresentariam, segundo Adorno, um nexo intrínseco (em sua forma, e não em seu conteúdo) com a reificação, pela via de sua estrutura conceitual, que, ao invés do pretendido, afastaria o sujeito do conhecimento do objeto. Esta seria inclusive uma das conclusões da Dialektik der Aufklärung, em sua apresentação do modo de correspondência entre a sociedade alienada e administrada e a racionalidade sistematizadora, classificatória, calculista, identificadora. Haveria um domínio reificado da falsa objetividade no pensamento resultante da dialética entre dominação da natureza e dominação social.

No plano delimitado entre materialismo dogmático, fenomenologia e positivismo, Adorno seria influenciado por três pensadores: Lukács, Benjamin e Horkheimer. Eles defendem posições muito semelhantes quanto à superação dos problemas do materialismo, mediante um materialismo nãodogmático em diálogo com a metafísica (ver, por exemplo, A Schmidt; S. Jarvis; S Buck-Morss, Gillian Rose, H. Hesse, G. Bolte, E. Lunn, entre outros).

Georg Lukács situa a discussão do tema numa reificação objetiva, insistindo na perspectiva do conhecimento de si da realidade efetiva frente à prioridade do sujeito cognoscente idealista. Benjamin amplia a questão, ao chamar a atenção para a questão da reificação da própria experiência, e insistindo num pensamento que contemple a empiria não refletida conceitualmente mediante constelações e imagens dialéticas. Por fim Horkheimer insiste na racionalidade a preservar para a apreensão do não-idêntico, no âmbito de uma teoria crítica a partir de uma filosofia enriquecida pela interação com as ciências.

Segundo Adorno, como demonstra Rademacher (1993, p.44), impunhase uma crítica imanente ao "pensamento da identidade" - modo como resume os pressupostos idealistas - justamente para que o não-idêntico não fosse apreendido como "o outro da razão", numa "experiência" extra-racional. Adorno não identifica razão instrumental com pensamento identitário - por isso não procede a crítica sugerida por Habermas, de haver uma totalização ideológica na Dialektik der Aufklärung (Habermas, 1988, p.145) mas apreende identidade e não-identidade como antinomia no próprio âmbito da razão, seguindo aqui o programa de Lukács em História e consciência de classe.

Não se trata de um ceticismo em relação à razão, como também sugere Habermas (idem, p.156), mas sim de possibilitar à razão a liberação do não- 
idêntico nela contido. Este último não é desprovido de conceito, embora não seja por completo identificável conceitualmente. Brunkhorst sublinha como para Adorno o próprio conceito seria ele próprio antinômico quando referido ao não-idêntico (Brunkhorst, 1990, p.263).

Para Adorno o pensamento identitário se revelaria como incapaz de, pela sua via conceitual, dar conta dos objetos, embora essa seja sua pretensão explícita. Eis aqui os limites do que seria a tese do primado do sujeito, conforme o paradigma do sujeito constituinte da objetividade. A limitação se refere a um sujeito identificado como sujeito transcendental.

Adorno conceberia a tese do primado do objeto com intuito polêmico e não enquanto contraposição estrita (Guzzoni, 2003, p.28), para reabilitar, para determinar de uma outra maneira a objetividade do sujeito - como sujeito empírico real - e assim retirar o nexo sujeito-objeto da sua redução subjetivista idealista, possibilitando, ademais, uma apreensão mais aprofundada do objeto.

O primado ou a prioridade do objeto encontra-se numa relação dialética com a prioridade do sujeito e não em estrita oposição à mesma. Trata-se de romper, sem abandonar o conceito, a via da conceituação (Begrifflichkeit) no âmbito do pensamento identitário. A tarefa precípua do primado do objeto é justamente forçar o conceito a apresentar-se como antinômico. Seria neste sentido que Adorno, aliás, caracterizaria a dialética: apresentar "o novo no velho" (Adorno, 1989, v.5, p.46).

\section{A Tese do primado do objeto (Vorrang des Objekts) na obra de Adorno}

Como vimos a questão do primado do objeto já se encontra presente na Dialektik der Aufklärung. Além disso, constitui tema nuclear no ensaio Crítica cultural e sociedade, de 1949 - que inicia o livro Prismas - bem como em O ensaio como forma, escrito entre 1954-1958 (Jarvis, 1998, p.140). A expressão propriamente dita - primado do objeto - seria utilizada explicitamente a partir de 1962, conforme atesta o texto que reproduz um seminário oferecido por Adorno na Universidade de Frankfurt, sob o título Marx e os conceitos fundamentais da sociologia (Adorno, 1997). O "conceito" do primado do objerto seria elaborado particularmente na Dialética negativa e nos ensaios Sobre sujeito e objeto e Notas marginais sobre teoria e prática, de publicação póstuma. É usado também nos escritos - em publicação mais recente como Nachgelassene Schriften - relativos aos cursos, todos de 1965, dedicados à elaboração da Dialética Negativa, publicados nos volumes Metaphysik: Begriff und Probleme, Vorlesungen über Negative Dialektik e Zur Lehre von der Geschichte und von der Freiheit. 
Gillian Rose resume didaticamente o escopo da Dialética negativa: Adorno "pretendia providenciar uma base filosófica e sociológica para o estabelecimento do primado do objeto e a mediação entre sujeito e objeto, sem incidir numa posição que dava suporte à prioridade do sujeito" (Rose, 1978, p.61).

Neste empreendimento, Adorno acompanha o que denomina de segundo giro - ou segunda reflexão - copernicano efetuado por Hegel em sua formulação da "verdade não só como substância, mas como sujeito" do Prefácio da Fenomenologia do espírito, em que se reconstrói a gênese das determinações do sujeito. Esta é apreendida como crítica ao "eu penso" transcendental que deveria "acompanhar todas as nossas representações" segundo a famosa dedução transcendental da Crítica da razão pura.

Mas simultaneamente Adorno critica em Hegel a solução no plano do espírito como totalidade, que reduziria pela "espiritualização" (Vergeistigung) a realidade efetiva ao estrito âmbito conceitual. Em que pese o formalismo de sua dedução transcendental, Kant, de sua parte, preservaria a realidade extra-conceitual em seu ser-em-si. O sujeito kantiano da "apercepção transcendental" é produtivo - o que inclui a matéria (Stoff) - e não estritamente auto-constitutivo, como a Tathandlung fichteana. Se Hegel faz a crítica do formalismo (o abstrato indeterminado), por sua vez reduz o conteúdo (determinação concreta) ao âmbito da consciência como figura da história do espírito, caracterizando em última instância uma solução no plano da razão subjetiva. Nestes termos seria preciso, no segundo giro copernicano, atentar ao primado do objeto, possibilitando assim evitar a identidade sujeito=objeto da solução hegeliana em sua espiritualização. Isto possibilitaria fazer, sem negá-la, a crítica de sua dialética conceitual limitada no plano da reconstrução cultural, mediante uma dialética negativa, no plano objetivo.

Em particular a leitura que Marx faria de Hegel seria uma referência importante para esta crítica do viés idealista da dialética, embora repetidas vezes Adorno registre também na obra marxiana posições positivistas que conduziriam, por sua vez, às formulações do cientificismo marxista, como na obra de Engels. Conforme Adorno, a obra de Hegel possibilitaria uma leitura para além do plano do espírito e da identidade sujeito-objeto, sem renúncia à dialética. Essa aliás é a interpretação pela perspectiva "marxiana" da Fenomenologia do espírito feita pela leitura de Kojève - que sai do plano geral do espírito das relações senhor-servo, para a concretude material do servo, que não é intelectual, mas trabalhador braçal - procura viabilizar, em que pese o imediatismo da sua aplicação materialista dos conceitos hegelianos, que pretende em Hegel o que é a leitura de Marx. Haveria na elaboração hegeliana, segundo Adorno expõe repetidas vezes em Três estudos sobre Hegel, um "resto empírico" não subsumido sob o espírito. 
Na obra de Adorno, por um lado, a objetividade material estaria presente empiricamente mas de modo mediatizado na figura de uma efetividade caracterizada no presente como "utópica". São possibilidades materiais efetivas não apresentadas como aparência no âmbito da construção idealcultural hegeliana e portanto acessíveis à experiência por uma "especulação" não regressiva, mas prospectiva, para a frente conforme uma consciência do possível. Por outro lado, porém, seriam realmente acessíveis à "experiência" como coisas fora do espírito, embora não realizadas. Este seria o cerne da experiência intelectual ou especulativa (geistige Erfahrung) que Adorno discute na Dialética negativa.

Pelo exposto, mesmo a superação hegeliana - pela via da mediação sujeito-objeto - do duplo giro copernicano de Kant ainda permaneceria nos parâmetros da prioridade do sujeito, como demonstraria o sujeito-objeto idêntico que persiste na dialética. Frente a esse primado do sujeito, a tese do primado do objeto de Adorno permitiria compreender a afirmação de Grenz segundo a qual "Adorno é o acontecimento filosófico mais importante desde Kant" (Grenz, 1984, p.262).

Conforme Adorno, a prioridade material objetiva não redunda em "objetivismo"; isto é, não anula a razão. Ao contrário: o tema da prioridade do objeto se instala justamente porque, como já se constata em Crítica cultural e sociedade, a prioridade do ser sobre a consciência tem servido, conforme seu conteúdo de verdade de acordo com uma 'intentio recta', sobretudo ao conformismo em relação ao vigente característico do positivismo. Não teria havido no trajeto marxiano de crítica aos hegelianos de esquerda, ao contrário do anunciado, uma revisão adequada do giro kantiano em direção ao sujeito e seu direcionamento ao interesse subjetivo de liberdade mediante um ato da vontade. A questão seria elaborada no quarto item de Sobre sujeito e objeto, onde se caracteriza com clareza a prioridade do objeto como movimento em que "o sujeito há que ser conduzido à sua objetividade" (Adorno, 1989, v.10-2, p.749):

Primado do objeto quer dizer que o sujeito é por sua vez objeto num outro sentido, mais radical do que objeto, porque não pode ser conhecido senão mediante a consciência, também é sujeito. O que se conhece mediante a consciência precisa ser algo, a mediação remete ao mediatizado (...) A objetividade pode ser pensada potencialmente, embora não atualmente, sem sujeito; mas o mesmo não ocorre com a subjetividade e o objeto. (...) Se o sujeito não é algo - e "algo" designa um momento objetivo irredutível - então não é nada; até enquanto 'actus purus' necessita a referência a um agente. O primado do objeto é a 'intentio obliqua' da 'intentio obliqua' e não a requentada 'intentio recta'; o corretivo da redução subjetiva e não o renegar de uma participação subjetiva. Também o objeto é mediatizado, mas não conforme o próprio conceito de modo tal que remete tanto ao sujeito como o sujeito remete à objetividade. (Adorno, 1989, v.10-2, p.746) 
Na Dialética negativa Adorno caracterizaria o primado do objeto no nexo sujeito-objeto em contraposição a qualquer paralelismo entre ambos em sua relação recíproca.

A mediação do objeto significa que (...) só pode ser conhecida em seu entrelaçamento com a subjetividade; (mas) a mediação do sujeito (significa) que literalmente este seria nada sem o momento da objetividade. (Adorno, 1989, v.6, p.184)

Em resumo, conclui-se do exposto que a tese do primado do objeto possui um duplo significado, seja no que concerne o sujeito, seja no que diz respeito ao objeto.

I. Pelo primeiro significado, no âmbito do nexo sujeito-objeto ambos se encontram reciprocamente determinados e "abertos um para o outro." (Guzzoni, 2003, p.31)

Quanto ao sujeito, ele é o sujeito do conhecimento que por essa via "domina" o objeto, ao apreendê-lo subordinado ao geral; mas também é um objeto entre objetos, isto é, sujeito particular entre outros. O sujeito se refere

1. tanto às suas "determinações objetivas", que o condicionam face ao existente; ou seja, como o sujeito se adapta no âmbito da socialização: sujeito transcendental que a rigor, seria anulado como sujeito por sua determinação objetiva.

2. como também à "objetividade do sujeito", que caracteriza o mesmo como atividade efetiva concreta possível e não só estabelecida reconstrutivamente, como condição de possibilidade: isto é, como sujeito empírico. Em outros termos: como o sujeito mantém capacidade de interferir no contexto da construção social, pela autonomia vinculada à consciência das determinações objetivas que o condicionam, potencial de intervenção em nexo com uma possibilidade como algo qualitativamente novo no objeto e, portanto, crítico em relação ao contexto objetivo vigente. Como afirma Adorno em Sujeito e objeto, o que está em causa não é menos sujeito, mas mais sujeito. Não se trata de um anti-subjetivismo, mas de uma subjetividade contra o subjetivismo, a correção do primado do sujeito conforme Kant. Aqui se insere o comentário do texto final da primeira publicação da Dialektik der Aufklärung - não presente na versão publicada em 1947 - O esquema da cultura de massas (Adorno, 1989, v.3, p.299), onde Adorno se refere ao limite da reificação, na medida em que "os sujeitos são propriamente sujeitos" (objetivos) (Müller-Dohm, 1996, p.216).

O objeto, por seu turno:

1. é o que é determinado pelo sujeito, objeto que é pensado, objeto intencional, o que é apreendido conceitualmente, subordinado ao pensamento constituinte de objetividade.

2. mas é, também, independente frente ao sujeito, existente em si próprio, existência real. 
II. Mas há um segundo significado. Nos termos acima se destaca "uma análise da relação sujeito-objeto como sendo, em si mesma, assimétrica" (Guzzoni, 2003, p.27). O primado do objeto resulta numa nova apreensão do nexo sujeito-objeto, que desequilibra o que seria a harmonia entre estas determinações recíprocas de sujeito e objeto. O primado do objeto, tendo em vista o exposto, se refere não apenas ao nexo sujeito-objeto, mas ao próprio estatuto real de sujeito e objeto na relação entre pensamento e mundo. Nesta medida, conforme o primado do objeto, o próprio objeto tal como se apresenta como objeto instituído pelo sujeito transcendental, não se encontra fora da história, mas resulta de um processo produtivo efetivo no trajeto da própria objetividade histórica do sujeito. Aqui a tese do primado do objeto significa a nervura, o ponto onde "a dialética se torna materialista" (Adorno, 1989, v.6, p.193).

Na Dialética negativa Adorno (1989, v.6, p.10) explicita que se trata de romper "mediante a força do sujeito" o engodo da constituição da subjetividade que a aprisiona. Somente o sujeito enquanto objeto - e não sujeito transcendental constituinte - estaria apto a desenvolver uma "experiência filosófica" apta a apreender a objetividade para além de ela ser objeto para um sujeito cognoscente. Deste modo haveria a possibilidade da superação da constituição da experiência no âmbito do conhecimento tal como proposta por Kant. Mas este "momento subjetivo" de pré-formação da experiência também é objetivamente mediado pela totalidade social. Como destaca em sua análise Jürgen Naeher, "a teoria do conhecimento assim depende de e remete à teoria social, a uma teoria crítica do conhecimento 'do processo social material de produção' (Adorno, 1989, v.6, p.22)" (Naeher, 1984, p.183).

A totalidade referida não seria mais a "totalidade de sentido" no âmbito da teoria do conhecimento, recuperada filosoficamente. Teria a ver sobretudo com uma nova apreensão da totalidade em harmonia com a experiência, que Wolfgang Bonâ denomina "empiria da totalidade" (Bonâ, 1982, p.182; ver a respeito tb Jay, 1984). Esta diferença na apreensão da totalidade constitui a chave da leitura adorniana de Hegel: a distinção entre o "espírito" como trabalho social, onde se realiza objetivamente e a "espiritualização" do espírito na "totalidade" (hegeliana de sentido), esta última sendo "o todo que é o não verdadeiro" (Adorno, 1989, v.4, p.55).

\section{Gênese filosófica do primado do objeto como crítica ao Idealismo no trajeto Kant-Hegel}

Na história da filosofia cabe "escapar do aprisionamento no contexto conceitual” (Adorno, 1989, v.6, p.189). Isto diferencia a dialética negativa da 
dialética conceitual reconstrutiva de Hegel como sendo uma experiência intelectual (geistige Erfahrung). Isto é, a experiência das possibilidades do objeto que não estão expressas na sua aparência no âmbito da consciência - fora da apreensão da essência hegeliana ("é essencial à essência aparecer como aparência") e, portanto, da dialética da reconstrução - e que ao se efetivarem, negariam a realidade vigente existente.

Pelo acima exposto, à dialética negativa não basta uma fenomenologia, na medida em que a aparência socialmente necessária termina por ser uma reafirmação do existente. A relação com a teoria seria diversa, pois cabe levar em conta o primado do objeto, donde deriva a medida para avaliá-lo. Ou seja, as mediações sociais que, como um todo, enquanto sistema social, influenciam as necessidades do objeto e que este apresenta como tarefas ao sujeito - o que seria o "conceito" a ser confrontado com o existente, a essência da sociedade -, requerem uma interpretação para poder haver a transformação, opondo-se assim a uma leitura simplista das prioridades da famosa $11^{a}$ Tese sobre Feuerbach, segundo a qual os homens apenas interpretaram o mundo. Isto é explicitado no ensaio póstumo Notas marginais sobre teoria e prática dos Epilegômenos dialéticos.

O primado do objeto precisa ser respeitado pela práxis: a crítica do idealista Hegel à ética da convicção moral kantiana explicitou isto pela primeira vez. Apreendida de modo correto, a práxis, na medida em que por seu turno o sujeito é uma mediação, é aquilo que o objeto quer: ela segue suas necessidades. Mas não mediante adequação do sujeito, que a objetividade heterônoma meramente consolida. As necessidades do objeto são mediatizadas pelo sistema social total; por isto são determináveis apenas através da teoria. (Adorno, 1989, v.10-2, p.766)

O primado do objeto se contrapõe, seja ao primado do sujeito, a intentio recta, seja ao primado da práxis material que "se fixa pragmaticamente no próximo passo" (ibidem). O critério de verdade da avaliação da realidade Realitätsprüfung (idem, p.767) - não pode se apoiar no objeto em sua formação vigente, mas precisa levar em conta o objeto inclusive como objetividade do sujeito nos termos antes assinalados - a 'intentio obliqua' - , expostos a partir da interpretação teórica apreendida como decifrar, como Deutung. O decisivo, que proporciona o padrão de medida (Maâgebende), vincula-se a uma tal "teoria objetiva da sociedade, que apreende a mesma como autonomizada frente à vida" (idem, p.773). Esta verdade como "contradição (é) a única com chance de ser frutífera" (idem, p.781); isto é, a contradição é objetiva.

O âmbito conceitual seria apreendido por Adorno como sendo dotado de objetividade. Assim ele adverte em um texto de curso de 1962, Marx e os conceitos fundamentais do marxismo, que "os conceitos não existem apenas na cabeça dos filósofos, mas estão na realidade efetiva das coisas elas 
próprias, de modo que quando falamos da essência designamos precisamente o que a sociedade, sem saber, já possui em si" (Adorno, 1997, p.503). Mas, adverte Adorno no seminário antes referido, esta objetividade do conceito não é a objetividade do realismo conceitual em sua mistificação e sim a objetividade do "primado do objeto frente ao conceito" (idem, p.504), a prioridade do fato "inescrutável" (ibidem) frente ao "outro".

Estaria em pauta aqui um "ser-em-si" distinto da estrita inteligibilidade do kantiano, a saber: o conceito dotado de um momento "empírico", material, que estaria no "individual sem o qual a teoria crítica seria vazia" (Adorno, 1989, v.10-2, p.781). Sonnemann explicita este momento como sendo um "ser-em-si inteligível do mundo fenomênico, ele próprio como aparente (Erscheinender)" (Sonneman, 1990, p.114).

Para Adorno, o problema deste ser-em-si para além da estrita inteligibilidade se evidenciaria, por exemplo, na Fenomenologia do espírito.

Em Hegel o espírito é designado como totalidade. As determinações do trabalho não são determinações de um princípio espiritual separado, mas Hegel pensa numa interação do homem com a natureza, só que o movimento conjunto é interpretado como de um espírito. Mas os momentos do trabalho são também momentos materiais e não atividades de um espírito isolado. O servo não é um intelectual. O espiritual repousa apenas na relação geral que ocorre entre senhor e servo. Num certo sentido a objetivididade (Gegenständlichkeit) adquire significado mais finalizado do que em Marx, porque sobra um resto insolúvel do institucional frente a uma sociedade livre. (Adorno, 1997, p.505)

O primado do objeto tal como explicitado conduziria a uma "teoria objetiva da sociedade, como sociedade autonomizada em relação ao que vive" (Adorno, 1989, v.10-2, p.773). Para Adorno "os objetos não são imediatamente sujeitos, mas o subjetivo está presente também nos objetos, no sentido do que é necessário para a abstração" (Adorno, 1997, p.503), pela qual a "segunda natureza" da socialização aparece como se fosse "a primeira". Já Marx, segundo Adorno, nem sempre estaria atento a esta dimensão, que seria a "composição orgânica" do indivíduo, conforme o fragmento Novissimum organum, da Mínima moralia (Adorno, 1989, v.4, p.261) e a realização objetiva da "ideologia" como "falsa sociedade" referida em Crítica cultural e sociedade (Adorno, 1989, v.10-1, p.29). Esta situação caracterizaria a antropologia negativa de Adorno, que registra como "a mediação social efetivada pela categoria do valor não permanece exterior aos produtos do trabalho, mas infiltra a própria organização da produção" (Breuer, 1985, p.17).

Adorno certamente seria influenciado aqui pelas contribuições de Henrik Grossmann na Revista de Pesquisa Social, em que este autor sustenta a objetividade criada no processo com que a acumulação capitalista se impõe socialmente (Schlüter, 1997, p.569). Os conceitos indústria cultural e semi- 
formação são largamente tributários de tal perspectiva teórica. Deste modo também se inserem na tese do primado do objeto, necessária para a atividade que neles se representa como consolidação da socialização vigente.

A tese do primado do objeto se origina de uma dupla relação crítica com a trajetória de Kant a Hegel constitutiva do idealismo alemão.

I. Em relação a Kant, Adorno tem em alta conta que o chamado "giro subjetivo" não é uma mera criação subjetiva, mas que nele o sujeito se instala como "fiador" da objetividade, isto é, da validade do conhecimento (Adorno, 1995a, p.56). Esta seria a "novidade" (ibidem), que o distancia de Hume, por exemplo: em Kant "o segredo da subjetividade é algo objetivo, o poder da objetividade", de resto uma objetividade "determinada que constitui o pressuposto de subjetividade"(idem, pp.192-3). Isto é o que há de verdadeiro no "giro copernicano"de Kant, algo como "uma conseqüência negativa da preponderância do espírito"(Kager, 1988, p.160): o rompimento do domínio subjetivo face à barreira historicamente estabelecida entre objeto e sujeito.

Ao mesmo tempo Adorno censura a Kant o formalismo da dedução transcendental, enquanto é a fundação da objetividade mediante subjetividade, conforme a tese da revolução copernicana (Allkemper, 1981, p.79). Nesta medida Adorno assevera nos fragmentos que pretendia publicar sob o título Graeculus, a necessidade de "'retirar' (Zurücknehmen) a Crítica da razão pura" (Adorno, 2003a, p.20). A constituição da objetividade pelo sujeito, quando distanciada da reflexão, isto é, quando há uma hipostasia do sujeito, corre o risco de conduzir a lógica transcendental num retorno à lógica formal, e o pretenso conhecimento se reduz a uma tautologia (Schlüter, 1987, p.300), uma mera "duplicação" (Naeher, 1984, p.247). Impõe-se, portanto, uma "segunda reflexão" (Gripp, 1986, p.104), um segundo giro copernicano (Achsendrehung ou Wendung) (Adorno, 1989, v.6, p.10; Adorno, 1989, v.10-2, p.746). A esta segunda reflexão caberia revelar o limite do conhecimento - a transcendência - no âmbito de uma "gênese histórica contingente" com uma dupla conseqüência: seja que há uma determinação objetiva desta constituição subjetiva, seja que a mesma não constitui incondicionalmente a verdade definitiva. Assim Adorno transita da revolução copernicana - que já não é só um "giro para o sujeito", mas um giro refletido - ao primado do objeto, com um duplo significado. De um lado, a

relativização da subjetividade, cujos potenciais Adorno reconhece como sendo pervertidos com base na experiência antropológica da espécie. (De outro lado a subjetividade como...) "força construtiva" na medida em que surge do primado do objeto um impulso crítico para o pensamento. Tal dialética seria uma dialética materialista. (...) Somente o sujeito é capaz de fixar a contradição, ao pensá-la, utilizando-a como impulsora do pensamento. (Gripp, 1986, p.105) 
Assim tanto o eu empírico entre outros, quanto o "eu penso" como "puro" sujeito transcendental tem uma referência empírica. A subjetividade é a forma do objeto e a identidade subjetiva consiste no "ato" da transcendência. Forma que precisa ser realizada subjetivamente pelo sujeito "conforme as necessidades do objeto", destaca Paetzold em relação à estética adorniana (Paetzold, 1975, p.85). Como a própria razão, para Adorno a subjetividade não é nem só empírica, nem só transcendental, mas ambos. "Não apenas o objeto cartesiano é empírico, mas também o é o 'eu'" (Arato \& Gebhardt, 1997, p.402).

II. Para Adorno, Hegel chegara bem próximo a este "segredo" oculto na síntese da apercepção. Gripp mostra como, de um lado, o espírito, identificado por Hegel como determinante de todos os momentos individuais isolados e, portanto, também de todos os atos isolados do pensamento, seria apreendido por Adorno como "sociedade" (Gripp, 1986, p.99). "A sociedade é tão essencialmente conceito como o espírito" (Adorno, 1989, vol .5, p.274).

Mas, de outro lado, sob a égide da totalidade, Hegel espiritualiza esta mediação de toda individualidade através de uma objetividade, reunindo hermeticamente os momentos individuais num nexo reificado, pondo a perder a dialética entre o individual e o geral (Gripp, 1986, p.100). "Dissolveu no plano do pensamento a diferença entre o condicionado e o absoluto, conferindo ao condicionado a aparência do incondicionado" (Adorno, 1989, v.5, p.324). O trajeto Kant-Hegel, iniciado com a crítica da formalização, termina por escamotear a crítica à totalidade espiritualizada, a sociedade como "espiritualização", como nexo reificado, de modo que "a relação com este todo é fictícia", não verdadeira (ibidem).

No escrito póstumo Graeculus, podemos acompanhar ainda uma vez com clareza esta dupla relação com Hegel, num fragmento de 1959, intitulado Ad ontologia e dialética:

Na transição ao fundamento real, Hegel constatou muito bem o problema do não-idêntico: ele aparece sob o título de "realização". Mas (...) Hegel acredita que, por ser determinável apenas enquanto conceito, o não-idêntico tenha sido removido, trazido à identidade. E há que concordar que o não-idêntico não é um imediato, mas é mediatizado. Mas precisamente neste ponto Hegel foi muito pouco dialético, isto é, o não-idêntico é idêntico e não-idêntico; e seu próprio conceito, que o torna em idêntico, em igualdade consigo próprio, possui como seu conteúdo a sua não-identidade; sem esta não existe identidade, assim como não existe o não-idêntico sem a identidade, ao passo que esta acaba por assumir, na totalidade, a prioridade ontológica em Hegel. (Adorno, 2003a, p.11)

A questão da "realização" referida acima remete, enquanto "realização pelo trabalho", ao texto do seminário Marx anteriormente citado (Adorno, 
1997, p.505), em que Adorno evoca um "resto empírico" para além da "totalidade" do espírito na Fenomenologia do espírito. Aqui é decisivo registrar que, na leitura de Adorno, o "espírito" representaria para Hegel o trabalho social, enquanto a "totalidade" caracterizaria, como "espiritualização" (Vergeistigung), a sociedade como socialização reificada. Deste modo, para Adorno o argumento idealista da inexistência de conhecimento sem o sujeito que conhece, não implica "nem que um objeto existe apenas mediante seu conhecimento, nem (que há) uma 'prerrogativa ontológica da consciência'" (Haag, 1985, p.162).

A objetividade retraduzida "para fora" da espiritualização idealista facultaria o materialismo à dialética e constitui a tese do primado do objeto. Tal objetividade seria acessível pela "experiência espiritual", conceito já presente nos Três estudos sobre Hegel, mas explicitada na Dialética Negativa e nos seus cursos preparatórios. Trata-se de uma espécie de "especulação indutiva". Ou seja: aqui Adorno redimensiona o conceito de experiência kantiano, tal como este se encontra restrito no meio da reflexão conceitual de um conhecimento apreendido na esteira da dedução transcendental "de cima para baixo", mediante uma experiência "de baixo para cima" (Adorno, 2003, p.122). Além disto, esta experiência seria dotada de um caráter inteiramente diverso do ideal empirista, que é simples "exemplo de categorias" deduzidas, para ser a possibilidade do "novo", a possibilidade da experiência de um "outro" não limitado pelas regras da dedução (idem, p.123).

No ensaio Aspekte, dos Três Estudos sobre Hegel, Adorno explicita a base desta experiência do novo.

(Em Hegel) já se impõe a constatação de que (...) a consciência moral não propicia a ação reta e justa e que o mero aprofundamento do eu no que deve ou não deve ser feito se enreda em contra-senso (...) não contrapõe o bem à vida empírica como princípio abstrato (...), mas vincula o bem em seu próprio conteúdo à constituição de um todo verdadeiro - justamente o que se instala na Crítica da razão prática como humanidade. Por esta via Hegel transcende a separação burguesa entre o ethos como uma determinação incondicional obrigatória, mas apenas válida subjetivamente, e a objetividade aparentemente apenas empírica da sociedade. (Adorno, 1989, v.5, p.292)

O contra-senso de um todo antagônico "cristaliza um conceito de experiência que aponta para além do idealismo absoluto" (Adorno, 1989, v.5, p.314).

Conforme Adorno, a crítica de Hegel à ética da consciência moral kantiana já havia exposto esta perspectiva. O ensaio Aspekte explicita como a posição de Hegel resultaria na crítica à própria categoria da individualidade. Hegel 
foi o primeiro a assinalar que a cisão entre o eu e o mundo perpassa mais uma vez o eu (...) cindindo o indivíduo conforme sua racionalidade objetiva e subjetiva de sua vontade e sua ação. Cedo ele percebeu que o indivíduo é ele próprio tanto indivíduo que funciona socialmente, determinado pela "coisa", ou seja, por seu trabalho, bem como uma essência para si própria, com tendências, disposições e interesses específicos, e que estes dois momentos apontam em direções contrárias. (Adorno, 1989, v.5, p.291)

Por essa via, Hegel estaria apto a evitar a contraposição do "Bem" como sendo um princípio abstrato frente ao eu empírico - justamente a sua crítica a Kant. A ação deixa o âmbito de uma subjetividade moral da consciência-de-si, para se verificar no âmbito de uma relação recíproca entre consciências-de-si de que resulta o dinamismo da "coisa mesma" hegeliana. Esse é o trajeto cultural-formativo, a Bildung da consciência-de-si, conforme os termos hegelianos. Nesta, em termos de uma referência conceitual já marxiana, pode-se afirmar, como Adorno, que "a práxis é o que o objeto quer", mas não mediante mera adaptação ao mesmo objeto, que simplesmente "consolida a objetividade heterônoma" (Adorno, 1989, v.10-2, p.766). O que o objeto quer, a necessidade do objeto, é mediatizada pelo sistema social e este precisa ser apreendido criticamente, o que por sua vez constitui a tarefa da teoria. Nas palavras de Adorno, "a reflexão do sujeito sobre o seu próprio formalismo é a reflexão do mesmo em relação à sociedade" (Adorno, 1989, v.10-2, p.757).

Cabe aqui recuperar os termos da crítica de Marx a Hegel. Este, diz Marx, apreendera em sua Fenomenologia do espírito de modo correto o trabalho como essência dos homens, porém o mundo em que contextualizara sua análise seria regido por uma situação contrária: a dominância do trabalho alienado, ou seja, do capital. Em sua lógica das necessidades, Hegel afinal apresentaria o ser genérico dos homens não como sendo fim, mas meio para a reprodução dos homens em sua existência vigente.

O trabalho, neste sentido da leitura marxiana de Hegel, tanto deforma os homens no âmbito da sociedade vigente, subordinando o ser genérico à reprodução material concreta, como também forma os homens numa direção que se contrapõe à mesma, para além das imposições destas condições sociais da mera adaptação do ser genérico à reprodução vigente.

Para Marx o trabalho social, como se sabe, é social num duplo sentido. É social primeiramente porque se realiza na troca e na divisão de trabalho etc.. Mas é social também no sentido em que se dá sob a forma social, isto é, socialmente determinado pelas condições sociais vigentes. Nesta medida a duplicidade social do trabalho traduz uma dupla característica do trabalho, que se instala já nos Manuscritos econômico-filosóficos como resposta à questão "Como os homens alienaram seu trabalho pelo trabalho?". 
Os homens em sua práxis social - cujo modelo é o trabalho social - produzem trabalho alienado que os mantêm adaptados às determinações sociais que refluem sobre sua própria práxis social. Isto exige uma adequada perspectiva de análise, apresentada por Marx nos seguintes termos:

Os economistas circunscritos nos limites das representações capitalistas sem dúvida percebem como se produz 'no interior' da relação capitalista, mas não percebem como esta 'relação' ela própria é produzida e ao mesmo tempo nela são produzidas as condições materiais de sua dissolução, eliminando-se assim sua 'justificativa histórica' como 'forma necessária' do desenvolvimento econômico, da produção da riqueza social. (Marx, 1969, p.81)

Isto é: Marx atenta não só aos mecanismos no âmbito da sociedade estabelecida, mas, sobretudo, à própria produção desta sociedade. Este último seria precisamente o plano em que a subjetividade é efetivamente constitutiva da sociedade, momento do primado objetivo do sujeito. Este, tal como o valor de uso em relação ao valor de troca, não pode ser liquidado, por mais que a continuidade da ordem social vigente se verifique por intermédio da formação de sujeitos meramente adaptativos e adaptados, ou mediante a geração de necessidades de valores de troca, tal como ocorre na socialização capitalista hoje existente.

A principal advertência de Adorno, como já exposto anteriormente, consiste em diferenciar o primado do objeto do primado da objetividade existente. A objetividade existente consiste, afinal, apenas na "dissolução do sujeito" (Adorno, 1989, v.4, pg 6). Esta diferenciação é focalizada particularmente na perspectiva do primado do objeto, como relação entre "objetividade" e "reificação".

\section{A Tese do primado do objeto e a questão da reificação (Verdinglichung)}

No início da Dialética negativa Adorno destaca a necessidade da filosofia:

Filosofia, que parecia ultrapassada, se mantém viva porque o momento de sua efetivação foi perdido. O julgamento sumário de que ela apenas teria interpretado o mundo, encontra-se deformado inclusive em si mesmo. Converte-se no défaitismo da razão, depois que a transformação do mundo deu errado. (Adorno, 1989, v.6, p.15)

A filosofia constitui momento da realidade, no sentido em que os problemas reais existem nela como momentos a demandarem focalizações filosóficas, como o julgamento antes referido. A transformação do mundo ocor- 
reu, mas não no sentido da filosofia da história; antes esta "mudou"; isto é: nela se apresenta a transformação do mundo. A "equação" de Horkheimer e Adorno é precisa: "O elemento é a liberdade, mas o tema é a opressão" (Adorno, 1989, v.3, p.247). Aqui se apresenta, como sublinha Buck-Morss, a originalidade de Adorno em articular a substância material com seus argumentos teóricos (Buck-Morss, 1981, p.360). Em sua Einleitung in die Soziologie (Introdução à sociologia), que contém as notas de um curso do mesmo título, Adorno explicita com muita clareza a questão em termos sociais, ao expor como os próprios sujeitos e a consciência fazem parte da ideologia:

Também os sujeitos fazem parte da sociedade e, para que a sociedade possa se conservar em sua forma vigente, necessitam-se sujeitos numa determinada situação. Se os sujeitos fossem diferentes, ou se eles fossem emancipados, como se afirma com freqüência e de modo procedente, então provavelmente a sociedade não poderia se conservar à maneira vigente, apesar de todos os meios impositivos. (Adorno, 1993, p.253)

Ocorre assim uma persistência do plano da subjetividade apreendida em termos idealistas. As idéias, na medida em que foram "apreendidas como forças efetivas na história, e esta última, apreendida como triunfo daquelas, perderam a ingenuidade, a ausência de compromisso (Arglosigkeit) que faz parte de seu conteúdo" (Adorno, 1989, v.3, p.255). Assim, para apresentar esta perda, a filosofia permanece necessária para o materialismo; não enquanto uma eventual imposição subjetiva, mas por derivação da própria objetividade da situação de que a própria filosofia participa. Trata-se de uma imposição interna. Ou seja: como o estado do pensamento se relaciona à situação objetiva, há problemas - como a consciência e as idéias que demandam apreensão do ocorrido no plano da filosofia, tal como apresentado pela tese do primado do objeto, fundamental para apresentar o ocorrido com a "consciência". Este é o nexo entre dominação da "natureza externa" e "dominação da natureza interna" exposto, por exemplo, na Dialektik der Aufklärung.

Adorno já desenvolvera a questão do nexo entre substância material e reflexão teórica de modo especial em 1942, em dois ensaios: Thesen über Bedürfnis e Reflexionen zur Klassentheorie. Neles mostra que há uma apreensão naturalizada e a-histórica das necessidades, bem como uma idealização das classes que exclui a experiência de classe e impede uma adequada apreensão das mesmas como objetividades efetivas, devida a uma inadequada apreensão da questão de sujeito e objeto pela crítica ideológica materialista.

No materialismo o problema da relação entre subjetividade e empiria "deixa de ser visto" (Jarvis, 2004, p.96); a critica ideológica desmistificado- 
ra apresenta dificuldades em perceber o encantamento em que ela própria se encontra presa (Jarvis, 2004, p.95).

As ilusões socialmente produzidas impactam o materialismo dogmático pela inaptidão a uma experiência efetiva da objetividade social. Nesse sentido o aprofundamento filosófico do problema das relações dialéticas entre sujeito e objeto se impõe para um materialismo não dogmático.

O primado dialético do objeto constitui, nesta medida, por exemplo, a possibilidade de retirar a questão da reificação (Verdinglichung) do plano subjetivo em que Lukács a dispusera. Não porque apreendera a reificação como questão no plano da consciência (o que não fez), mas porque reificação e consciência de classe são tratadas sem uma adequada apreensão da objetividade, permanecendo assim limitadas no plano dos pressupostos idealistas do primado do sujeito, de idéias que perderam a referência de parte de seu conteúdo, como antes assinalado. A distinção entre objetividade (Objektivität) e reificação (Verdinglichung) constitui um dos resultados fundamentais da perspectiva dialética do primado do objeto.

O primado do objeto tem a cabeça de Janus. Não só ele se apresenta aos diversos idealismos como sendo a verdade filosoficamente superior, mas constitui simultaneamente a expressão e crítica da situação do mundo, continuamente produzida pelos homens bem como alienada dos mesmos. O discurso do primado do objeto denuncia o que Marx denominara "a imposição muda" da situação das relações sociais. Adorno recorda aqui a famosa análise do fetichismo da mercadoria no primeiro volume de O capital. Marx sabe que, sem perda da prioridade do objeto, a "existência-em-si do mundo", sua "Dinghaftigkeit" também é ideologia: aparência socialmente necessária. (Schmidt, 2002, p.97)

Os homens seriam impelidos a apreender as suas próprias relações históricas de produção sob a forma de relações entre coisas. No caso desta situação, não se trata de um desvio ético (como pensavam os antigos), nem da astúcia do mercado (conforme a economia liberal), mas de uma falsa apreensão da objetividade dos próprios homens enquanto sujeitos do trabalho social, reduzidos como falsa objetividade à mercadoria, enquanto efetivamente constituem, como força de trabalho produtora de mais valia, produtores materiais efetivos de sua própria história e da formação social vigente (Jarvis, 2004, p.89).

Marx, afirma Adorno, já apresentara a diferença entre, de um lado, o primado do objeto a ser criticamente elaborado (Objetividade material efetiva) e, de outro lado, o primado do objeto em sua "careta" deformada no existente pelo caráter mercantil (Reificação). Por exemplo: "a troca tem objetividade real, enquanto ocorrência histórica material, e simultaneamente é objetivamente falsa, atenta contra seu próprio princípio, a igualdade, e 
por isso cria necessariamente falsa consciência, os ídolos do mercado" (Adorno, 1989, v.5, p.188).

A tese do primado do objeto constitui, pelo exposto, elemento indispensável à apresentação de uma teoria dos objetos. Apresenta-se assim um materialismo pela perspectiva do primado do objeto na experiência filosófica onde também a apreensão idealista da reificação, como em Lukács, seria submetida à crítica. Este seria um tema nuclear da Dialética negativa e da Teoria estética.

Acompanhar o pensamento de Adorno no trajeto centrado na apreensão da reificação nos termos expostos acima, possibilita examinar - pela perspectiva de uma teoria crítica e não tradicional formal, classificatória e dedutiva - em que medida Adorno se manteria preso aos pressupostos de uma "filosofia da consciência" conforme pretende, por exemplo, Habermas. Este, como é amplamente sabido, recrimina a Adorno e Horkheimer uma ideologização total da razão que conduziria a um ceticismo absoluto em relação à mesma (Habermas, 1988, pgs. 144 e 156). A focalização de Habermas carece de sustentação. O prisma do primado do objeto apresenta, justamente, elementos para a crítica e superação efetiva, material e histórica, da perspectiva dessa filosofia da consciência, ao estabelecer a prioridade materialista de uma reflexão apta a atingir o não-idêntico - como objeto - ou seja: a produção da objetividade e da subjetividade da razão. Em sua Teoria Estética Adorno denomina esta reflexão de "engajamento", "uma reflexão superior (...) que visa uma transformação das condições das situações" (Adorno, 1989, v.7, p.365) em vez de perdurar no mero plano de sua vigência.

MAAR, W. L. Materialism and priority of the object on Adorno. Trans/Form/Ação, (São Paulo), v.29(2), 2006, p.133-154.

- ABSTRACT: The thesis of the priority of the object, essential to Adorno's non dogmatic materialism, is analyzed in its constitutive elements, as a criticism of idealism which is present mainly at the works Dialectic of enlightenment and Negative dialectic. As a criticism of idealism, particularly on the relationships between reason and experience as first developed from Kant to Hegel, the thesis is based on Lukács, Benjamin, and Horkheimer contributions and is embedded on the perspectives of Marx and Nietzsche. With its disruption of symmetry between subject and object, the thesis of the priority of the object reveals the frailty of Habermas assertion, in his Philosophical discourse of modernity, of Adorno's and Horkheimer's skepticism towards reason. The present author argues that, in opposition to this claim, Adorno and Horkheimer contributed, with their new way of relating historical material and theoretical approach, to the analysis of the problem of reification in its relations to objectivity - as the non-identical - within the realm of reason, and not outside of it.

- KEYWORDS: Adorno; Materialism; Negative dialectic; Priority of the object; Critical Theory. 


\section{Referências bibliográficas}

ADORNO, Theodor W. Gesammelte Schriften in 20 Bänden. Darmstadt: Wissenschaftliche Buchgesellschaft, 1989.

- Einleitung in die Soziologie. Frankfurt am Main: Suhrkamp, 1993.

- Educação e Emancipação. São Paulo: Paz e Terra, 1995.

. Kants "Kritik der reinen Vernunft". Frankfurt am Main: Suhrkamp, 1995a.

- Probleme der Moralphilosophie. Frankfurt am Main: Suhrkamp, 1996.

. "Über Marx und die Grundbegriffe der soziologischen Theorie". In Backhaus, Hans-Georg. Dialektik der Wertform. Freiburg: Ça ira, 1997, p.501-13.

. Metaphysik: Begriff und Probleme. Frankfurt am Main: Suhrkamp, 1998.

- Ontologie und Dialektik. Frankfurt am Main: Suhrkamp, 2001.

. Vorlesungen über Negative Dialektik. Frankfurt am Main: Suhrkamp, 2003.

. "Graeculus. II: Notizen zu Philosophie und Gesellschaft". In Frankfurter Adorno Blätter - VIII, München: Text und Kritik, 2003a, p.9-41.

. Zur Lehre von der Geschichte und von der Freiheit. Frankfurt am Main: Suhrkamp, 2006.

ADORNO, Theodor W. \& BENJAMIN, Walter. Briefwechsel 1928-1940. Frankfurt am Main: Suhrkamp, 1994.

ALLKEMPER, Alo. Rettung und Utopie. Studien zu Adorno. Paderborn: Schöningh, 1981.

ARATO, Andrew \& GEBHARDT, Eike (Org.). The essential Frankfurt School reader. New York: Continuum, 1997.

BENJAMIN, Walter. Gesammelte Schriften in 7 Bänden. Frankfurt am Main: Suhrkamp, 2006.

BOLTE, Gerhard. Von Marx bis Horkheimer. Darmstadt: Wissenschaftliche Buchgesellschaft, 1995.

BONâ, Wolfgang. Die Einübung des Tatsachenblicks. Frankfurt am Main: Suhrkamp, 1982

BREUER, Stefan. "Adorno's Anthropology". In Telos, 64, 1985. p.13-31.

BRUNKHORST, Hauke. Theodor W. Adorno. Dialektik der Moderne. München: Piper, 1990.

BUCK-MORSS, Susan. Origen de la Dialéctica Negativa. México: Siglo Veintiuno, 1981.

GRENZ, Friedemann. Adornos Philosophie in Grundbegriffen. Frankfurt am Main: Suhrkamp, 1975.

. "Negative Dialektik mit offenen Karten: der zweite Teil der Negativen Dialektik". In Naeher, Jürgen (Org.). Die Negative Dialektik Adornos. Opladen: Leske und Budrich, 1984 .

GRIPP, Helga. Theodor Adorno: Erkenntnisdimensionen Negativer Dialektik. Paderborn: Schöningh, 1986. 
GUZZONI, Ute. Sieben Stücke zu Adorno. Freiburg: Karl Alber, 2003.

HABERMAS, Jürgen. Der philosophische Diskurs der Moderne. Frankfurt am Main: Suhrkamp, 1988.

HAAG, Karl Heinz. Der Fortschritt in der Philosophie. Frankfurt am Main: Suhrkamp, 1985

HEGEL, Georg. F. W. Werke in 20 Bänden. Frankfurt am Main: Suhrkamp, 1986.

HESSE, Heidrun. Vernunft und Selbstbehauptung. Frankfurt am Main: Fischer, 1984.

HORKHEIMER, Max. Gesammelte Schriften. Bd. 12. Frankfurt am Main: Fischer, 1985.

"Materialismus und Metaphysik". In Gesammelte Schriften. Bd. 3. Frankfurt am Main: Fischer, 1985a.

"Traditionelle und kritische Theorie". In Gesammelte Schriften. Bd. 4. Frankfurt am Main: Fischer, 1985b.

JARVIS, Simon. "Adorno, Marx, Materialism". In Huhn, Tom (Ed.) - The Cambridge Companion to Adorno. New York: Cambridge Un., 2004, p.79-100.

JAY, Martin. Marxism and Totality. The adventures of a concept from Lukács to Habermas. Berkeley: Un. of California, 1984.

KAGER, Reinhard. Herrschaft und Versöhnung. Frankfurt am Main: Campus, 1988.

KANT, Immanuel. Werke in 6 Bänden. Darmstadt: Wissenschaftliche Buchgesellschaft, 1986.

LINDNER, Burkhardt \& Lüdke, W. Martin. Materialien zur ästhetischen Theorie Th. W. Adornos Konstruktion der Moderne. Frankfurt am Main: Suhrkamp, 1980.

LUKÁCS, Georg. Geschichte und Klassenbewuâtsein. Darmstadt: Luchterhand, 1977.

LUNN, Eugene. Marxismo y Modernismo. Un Estudio Histórico de Lukács, Benjamin y Adorno. México: Fondo de Cultura Econômico, 1986.

MARX, Karl. Resultate des unmittelbaren Produktionsprozesses. Frankfurt am Main: Neue Kritik, 1969.

MARX, Karl \& ENGELS, Friedrich. Studienausgabe in 4 Bänden. Frankfurt am Main: Fischer, 1966.

MÜLLER-DOHM, Stefan. Die Soziologie Theodor W. Adornos. Eine Einführung. Frankfurt am Main: Campus, 1996.

NAEHER, Jürgen (Org.). Die Negative Dialektik Adornos. Opladen: Leske und Budrich, 1984.

PAETZOLD, Heinz. Neomarxistische Ästhetik: Adorno-Marcuse. Düsseldorf: Schwann, 1975.

RADEMACHER, Claudia. Versöhnung oder Verständigung? Kritik der Habermasschen Adorno-Revision. Lüneburg: Zu Klampen, 1993.

ROSE, Gillian. The Melancholy Science. An introduction to the thought of Theodor W. Adorno. London: Macmillan, 1978. 
ROSE, Gillian. "How is Critical Theory possible? Theodor W. Adorno and Concept Formation in Sociology". In Bernstein, Jay (Ed.). The Frankfurt School critical assessments, V.III. London: Routledge, 1994, p.154-172.

SCHLÜTTER, Carsten. Adornos Kritik der apologetischen Vernunft. Würzburg: Königshausen \& Neumann, 1987.

SCHMIDT, Alfred. "Adornos Spätwerk: Übergang zum Materialismus als Rettung des Nichtidentischen". In Fetscher, Iring \& Schmidt, Alfred (Eds.) - Emanzipation als Versöhnung: Zu Adornos Kritik der "Warentausch"-Gesellschaft und Perspektiven der Transformation. Frankfurt am Main: Neue Kritik, 2002, p.89-110.

SONNEMANN, Ullrich. "Die verwaltete Welt und das Unverfügbare". In Hager, Frithjof \& Pfütze, Hermann (Org.). Das unerhört Moderne. Berliner Adorno Tagung. Lüneburg: zu Klampen, 1990. 